\title{
Osteoarthritis of the hands and muscle strengthening exercises: an integrative update and review of the literature
}

\author{
Osteoartrite de mãos e exercícios de fortalecimento muscular: uma atualização e revisão \\ integrativa da literatura
}

Isabelle Ferreira da Silva Souza ${ }^{1}$, Rosa Sá de Oliveira Neta ${ }^{1}$, Renata Trajano Jorge Caldas ${ }^{2}$, Michely Nery ${ }^{3}$, Marcelo Cardoso de Souza ${ }^{1}$

DOI 10.5935/2595-0118.20180014

\section{ABSTRACT}

BACKGROUND AND OBJECTIVES: Osteoarthritis of the hands is a highly prevalent disease that can lead to significant deformity and disability. The therapeutic approach in the management of osteoarthritis of the hands is based on pharmacological and non-pharmacological approaches. However, none of these treatments demonstrated a reduction of joint damage, and it presents itself in a purely symptomatic way. Yet, expert practitioners strongly recommend and use hand muscle strengthening in patients with hand osteoarthritis, but there is no consensus for such conduct. The objective of the study was to review the concepts about hand osteoarthritis as well as to bring the current evidence on muscle strengthening as a non-pharmacological treatment for this disease.

CONTENTS: The study reviewed the United States National Library of Medicine database (Pubmed). The words used were: hand osteoarthritis, exercises, physiotherapy and rehabilitation. We included 5 articles in English, published in the last 10 years, focused on muscle strengthening exercises for osteoarthritis patients.

CONCLUSION: There is no consensus, nor a more effective exercise protocol, although exercises and physiotherapy are still recommended. We suggest conducting randomized controlled clinical trials to improve the evidence on this subject.

Keywords: Hands, Muscle strengthening, Osteoarthritis.

1. Universidade Federal do Rio Grande do Norte, Faculdade de Ciências da Saúde do Trairi, Programa de Pós-Graduação em Saúde Coletiva, Santa Cruz, RN, Brasil.

2. Faculdade Santa Terezinha, São Luís, MA, Brasil.

3. Universidade Federal de São Paulo, Disciplina de Reumatologia, Săo Paulo, SP, Brasil.

Submitted in April 16, 2017.

Accepted for publication in January 29, 2018

Conflict of interests: none - Sponsoring sources: none

Correspondence to:

Rua Vila Trairi, S/N, Centro

59200-000 Santa Cruz, RN, Brasil.

E-mail: marcelocardoso@facisa.ufrn.br

(C) Sociedade Brasileira para o Estudo da Dor

\section{RESUMO}

JUSTIFICATIVA E OBJETIVOS: A osteoartrite de mãos é uma doença altamente prevalente que pode levar à importante deformidade e incapacidade. A abordagem terapêutica no seu manuseio baseia-se em condutas farmacológicas e não farmacológicas; no entanto, nenhum desses tratamentos demonstrou redução da lesão articular e apresenta-se de maneira puramente sintomática. Contudo, profissionais especializados recomendam e utilizam amplamente o fortalecimento da musculatura das máos em pacientes com osteoartrite de mãos, mas não há um consenso para tal conduta. O objetivo do estudo foi revisar os conceitos sobre a osteoartrite de mãos, bem como trazer as evidências atuais sobre o fortalecimento muscular como forma de tratamento náo medicamentoso para esta doença.

CONTEÚDO: O estudo foi realizado na base de dados "United States National Library of Medicine" (Pubmed). As palavras utilizadas foram: "hand osteoarthritis", "exercises", "physiotherapy and rehabilitation". Foram incluídos 5 artigos em inglês, publicados nos últimos 10 anos, cujo foco fosse exercícios de fortalecimento muscular para pacientes com osteoartrite de mãos.

CONCLUSÁO: Não existe consenso, nem um protocolo de exercícios mais efetivos, embora os exercícios e a fisioterapia ainda sejam recomendados. Sugere-se a realização de estudos clínicos controlados e randomizados para melhorar a evidência sobre este assunto.

Descritores: Fortalecimento muscular, Mãos, Osteoartrite.

\section{INTRODUCTION}

According to the American College of Rheumatology (ACR), osteoarthritis $(\mathrm{OA})$ is defined as a heterogeneous set of conditions, causing signs and symptoms of joint origin associated to joint integrity defects and changes in the subchondral bone ${ }^{1}$. Among the rheumatological diseases, $\mathrm{OA}$ is the most common and frequently involves the hand joints ${ }^{2}$.

Characterized by the gradual injury to the joints associated to pain, degeneration of the subchondral bone, joint cartilage, and adjacent structures; OA of the hands involves mainly the proximal interphalangeal joints (PIJ) and distal (DIJ) and carpometacarpal joint (CMC) ${ }^{2,3}$. The alterations present in the joint cartilage and the subchondral bone result from the deficient function of chondrocytes to maintain the necessary balance of the extracellular matrix. However, the cause of the cartilage destruction is still unknown. Chemical and mechanical factors are associated with the onset of this condition ${ }^{4}$. 
Some risk factors are related to the development of the OA of hand, as for example age, female gender, family history, trauma, mechanical work factors and obesity ${ }^{3,5,6}$. Moreover, it is a highly prevalent disease, affecting between 55 and $70 \%$ of the adult population above 55 years, varying from 70 to $80 \%$ in individuals above of 75 years, and about $75 \%$ of the women between 6 th and 7 th life decade ${ }^{6,7}$.

The involvement of the PIJ, DIJ, and CMC can be characterized by some degrees of deformities, reduction of grasp and prehension muscle strength, reduction of the range of motion (ROM), the presence of pain and joint stiffness, reducing the capacity to perform basic daily activities ${ }^{8,9}$.

The classification of OA of the hand is made according to the ACR criteria, defined for symptomatic hands, based on the physical examination of the patient with pain in the hands, providing $92 \%$ of sensitivity and $98 \%$ of specificity. This proposed classification is based on the pain in the hands or joint stiffness in most of the days of the previous month, with 3 or 4 characteristics presented below:

- Joint swelling in two or more than 10 selected joints: second and third PIJ and DIJ or CMC of the hands;

- Joint swelling in two or more DIJ;

- Less than three swollen metacarpophalangeal joints;

- Deformity in two or more than 10 PIJ, DIJ and CMC joints.

The selected joints bilaterally include the PIJ, DIJ of $2^{\text {nd }}$ and $3^{\text {rd }}$ fingers and $\mathrm{CMC}^{1}$.

The classification of OA of hands, according to the European League Against Rheumatism (EULAR), assesses the following items: associated risk factors, mechanical pain and joint stiffness, presence of Heberden's and Bouchard's nodes, with or without joint swelling, reduction in hand function, association with other joints involved (knees and/or hip), evaluation of a differential diagnosis and $\mathrm{x}$-ray of the hand ${ }^{10}$.

The therapeutical management of the OA of the hands is based on pharmacological and non-pharmacological approaches. However, none of these treatments showed a reduction of the joint injury and presented in purely symptomatic way ${ }^{8}$.

In most of the cases, the pharmacological treatment of OA of the hands is directed by the symptoms presented by the patients, including analgesic, nonsteroidal anti-inflammatory drugs (NSAIDs), glucosamine sulfate, intra-articular injections and surgery in cases of severe OA of the hands. However, there are few disease-modifying drugs for OA of the hands, and the non-pharmacological measures are strategies to manage this condition ${ }^{8,11,12}$.

In 2012, the ACR published some recommendations for the use of pharmacological and non-pharmacological therapies for OA, including the treatment of the hands. However, these guidelines do not present an expressive degree of support, being conditioned to the patient's response. These recommendations ${ }^{13}$ are described in table 1 .

According to Zhang et al. ${ }^{14}$, the proper treatment for OA of the hands is based on the combination of individualized pharmacological and non-pharmacological modalities, in accordance with the patient's need.

Among this group of measures, the presented guidelines are: education of the patient, joint protection, local thermotherapy
Table 1. Recommendations for the treatment of osteoarthritis including the involvement of the hands

Pharmacological recommendations:

- The use of topical capsaicin and NSAIDs, oral NSAIDs, including selective COX-2 inhibitors, and tramadol;

- No use of intra-articular therapies, analgesics, and opioids;

- The use of NSAIDs in patients with and above 75 years of age.

Non-pharmacological recommendations:

- To assess the ability of the patient to perform daily life activities;

- Teach joint protection techniques;

- Teach the use of thermal modalities;

- Making prothesis for patients with OA CMC.

*These recommendations have a small to moderate level of evidence; NSAIDs = nonsteroidal anti-inflammatory drugs; $\mathrm{OA}=$ osteoarthritis, $\mathrm{CMC}=$ carpometacarpal joint.

(paraffin, hot bandage, ultrasound therapy), use of prosthesis, topical NSAIDs and capsaicin, paracetamol, oral NSAIDs effective low doses, extended-release symptomatic drugs for osteoarthritis, intra-articular injections with corticoids, especially for CMC joint, and surgery, for severe OA of the hands when the conservative treatment is unsuccessful. It is important to highlight that most of this evidence is based on the guidelines of experts in the management of OA of the hands ${ }^{14}$.

With regard to the measures to protect the joint, we can include the strengthening of the of the extensor muscles of the wrist and the intrinsic muscles of the hand. However, the best protocol is still unknown, especially because of the different methods to assess its efficacy and the great amount of selected exercises ${ }^{4,8,9,11,12}$. Among the group of non-pharmacological measures, it is also necessary to mention the importance of a diet standard and the nutritional state of the individual in the prevention and the treatment of OA. The advantage of the nutritional therapy can be obtained with a balanced and adjusted diet, with the habitual emphasis on micronutrients, fatty acids, flavonoids and phytochemicals that can be acquired eating fruits, fresh vegetables, skimmed dairy products, olive oil, and oil seeds. This can help to maintain the weight and bring antioxidant and anti-inflammatory benefits for the individual, allowing the reduction of the incidence or the progression of the musculoskeletal injury ${ }^{15,16}$. The objective of this study was to update the concepts on OA of the hands and to review the studies that have used the strengthening of the hand muscles as a non-pharmacological treatment for this disease.

\section{CONTENTS}

This is a literature review study conducted in the United States National Library of Medicine Database (PubMed). The following Health Sciences Descriptors (DeCS) and their combinations were used: hands osteoarthritis, exercises, physiotherapy, and rehabilitation.

The determinant inclusion criteria for the selection were full articles, available on the Internet and published in last the 10 
years. The exclusion criteria were descriptive studies that did not offer precise information on the methodology employed and/or results obtained, as well as abstracts of congresses, incomplete or paid articles, and those that did not have the terms used in the search as the main object of the study.

After the consultation to the database and the refinement of the searches, the studies in duplicate were identified and excluded. Then, all the remaining abstracts were read. In addition, in the cases where the reading of the abstract was insufficient to establish the inclusion of the article, considering the defined inclusion criteria, the article was read in full to determine its eligibility for later inclusion in the study. The search was conducted from December 2016 to January 2017, resulting in 925 articles, of which 5 about hand muscle strengthening exercises for patients with $\mathrm{OA}$ of the hands were included.

\section{RESULTS}

Of the 925 articles initially found in the database, 721 were excluded because they did not meet the inclusion criteria.

After that, of the 204 eligible articles, 66 were removed due to duplicity, and 133 were excluded after the search refinement. Thus, we had 5 articles in this review. Figure 1 summarizes the process of articles selection.

The selected articles had been published in 4 reputable journals: Journal of Rehabilitation Medicine (1) Annals of the Rheumatic Diseases (1), Osteoarthritis and Cartilage (2) and The Journal of Rheumatology (1).

Table 2 shows the articles, their authors, objectives, type of study and conclusions. Table 3 shows the sample size, the exercises performed and the results.

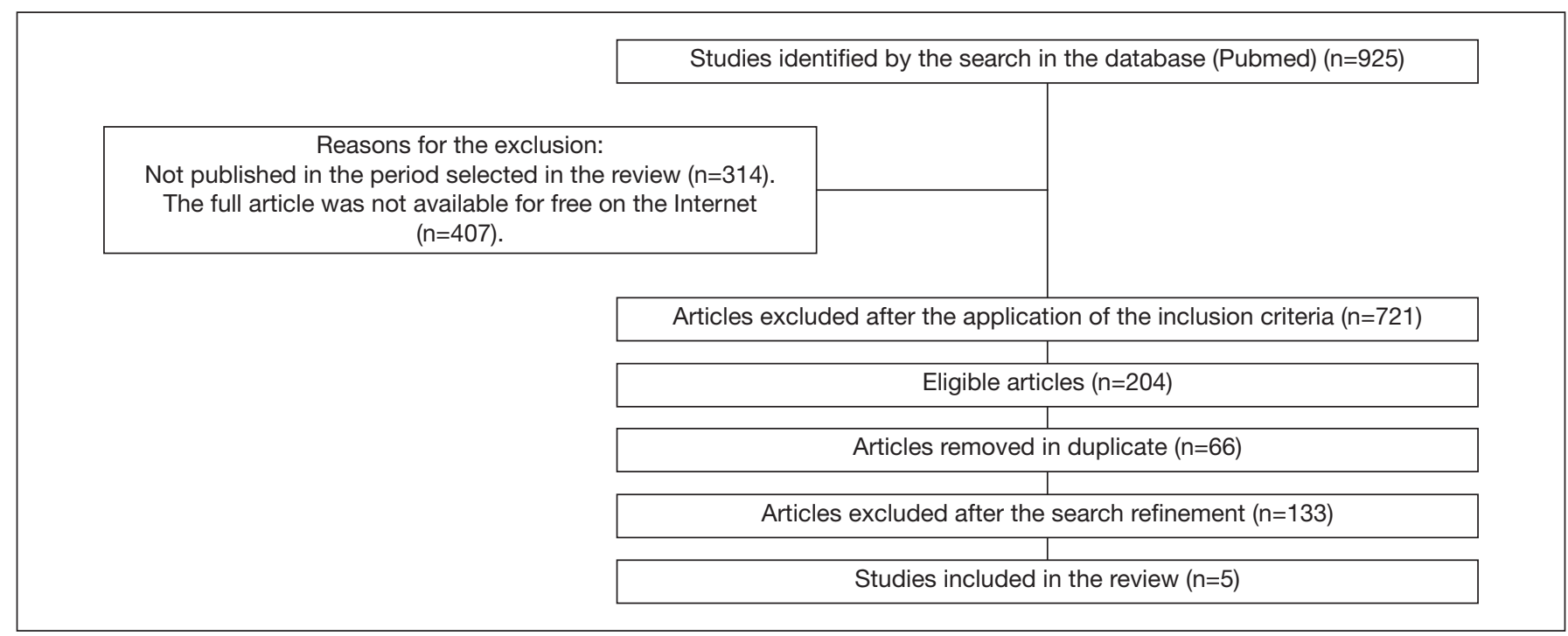

Figure 1. Flowchart of articles identification and selection

Table 2. Objectives and conclusions of the clinical trials on osteoarthritis of the hands and exercises for muscle strengthening in last the 10 years

\begin{tabular}{|c|c|c|}
\hline Authors & Objective of the studies & Types of stud \\
\hline $\begin{array}{l}\text { Østerås } \\
\text { et al. }{ }^{12}\end{array}$ & $\begin{array}{l}\text { To determine the clinical efficacy of an exer- } \\
\text { cises program on the function of the hand in } \\
\text { patients with OA of hands. }\end{array}$ & Clinical trial \\
\hline $\begin{array}{l}\text { Stukstette } \\
\text { et al. }{ }^{17}\end{array}$ & $\begin{array}{l}\text { To examine the efficacy of a multidisciplinary } \\
\text { non-pharmacological intervention in patients } \\
\text { with OA of hands. }\end{array}$ & Clinical trial \\
\hline $\begin{array}{l}\text { Carreira, } \\
\text { Jones and } \\
\text { Natour }^{18}\end{array}$ & $\begin{array}{l}\text { To evaluate the efficacy of a functional trape- } \\
\text { ziometacarpal splint in patients with trapezio- } \\
\text { metacarpal OA. }\end{array}$ & Clinical trial \\
\hline $\begin{array}{l}\text { Dziedzic } \\
\text { et al. }{ }^{19}\end{array}$ & $\begin{array}{l}\text { To report the results of a broad randomized } \\
\text { study to investigate the clinical efficacy of two } \\
\text { programs for adults over } 50 \text { years with OA of } \\
\text { hands. }\end{array}$ & Clinical trial \\
\hline $\begin{array}{l}\text { Oppong } \\
\text { et al. }{ }^{20}\end{array}$ & $\begin{array}{l}\text { To evaluate the cost-effectiveness of combi- } \\
\text { ned protective exercises for OA of hands. }\end{array}$ & Clinical trial \\
\hline
\end{tabular}

Conclusion

The exercise program was well tolerated by the individuals with OA of hands, but in comparison with the usual care, it produced only a slight improvement in short-term (after 3 months).

There is not enough evidence to confirm a clinically relevant effect in short-term in the patients followed in the multidisciplinary treatment program and those that have just received information in writing.

The results indicate that the use of the functional splint during daily life activities reduced pain in short- and long-term, but did not change the function, the prehension strength, the grasping strength or the dexterity in individuals with OA.

The results show that occupational therapies can support the treatment of the elderly with OA. Moreover, the joint protection provides an effective intervention in mid-term.

The results offer a choice for the patient and the health professional when selecting the best approach to manage OA of the hands. 
Table 3. Sample size, exercises performed and results of the clinical trials on osteoarthritis of hands and muscle strengthening exercises in last the 10 years

\begin{tabular}{|c|c|c|c|}
\hline Authors & Sample size & Performed exercises & Results \\
\hline Østerås et al. ${ }^{12}$ & $\begin{array}{l}\text { CG }(n=65) \\
I G(n=65)\end{array}$ & $\begin{array}{l}\text { Shoulder extension; biceps bending; } \\
\text { shoulder flexion; movements with the fingers } \\
\text { and the wrist; abduction/extension of the } \\
\text { thumb and squeezing strength. }\end{array}$ & $\begin{array}{l}\text { Small significant differences found in the IG for } \\
\text { pain in the hands, stiffness and daily activities; } \\
\text { No significant differences observed in manual } \\
\text { dexterity or maximum prehension strength. }\end{array}$ \\
\hline $\begin{array}{l}\text { Stukstette et } \\
\text { al. }{ }^{17}\end{array}$ & $\begin{array}{l}\text { CG }(n=75) \\
\text { IG }(n=76)\end{array}$ & Exercises with the wrist and fingers. & $\begin{array}{l}\text { No significant differences observed between the } \\
\text { groups. }\end{array}$ \\
\hline $\begin{array}{l}\text { Carreira, Jones } \\
\text { and Natour }{ }^{18}\end{array}$ & $\begin{array}{l}\text { CG }(n=20) \\
I G(n=20)\end{array}$ & Use of an orthosis for daily life activities. & $\begin{array}{l}\text { The pain was significantly different between the } \\
\text { groups over time. }\end{array}$ \\
\hline Dziedzic et al. ${ }^{19}$ & $\begin{array}{l}\text { IG }(n=65) \text { Joint protection } \\
\text { recommendation }(n=62) \\
\text { exercises CG }(n=65) \text { pro- } \\
\text { tection + exercises }(n=65)\end{array}$ & $\begin{array}{l}\text { Flexion and extension of the wrist, pronation and } \\
\text { supination; sliding tendon, radial finger walking; } \\
\text { doing an "O" with the thumb and the index fin- } \\
\text { ger, and extension of the thumb, abduction and } \\
\text { opposition to the base of the 5th finger. }\end{array}$ & $\begin{array}{l}\text { Significant differences were found in the impro- } \\
\text { vement of pain to joint protection. }\end{array}$ \\
\hline Oppong et al. ${ }^{20}$ & $\begin{array}{l}\text { Recommendation }(n=65) \\
\text { joint protection }(n=62) \\
\text { exercises }(n=65) \text { protec- } \\
\text { tion + exercises }(n=65)\end{array}$ & $\begin{array}{l}\text { Flexion and extension of the wrist, pronation and } \\
\text { supination; sliding tendon, radial finger walking; } \\
\text { doing an "O" with the thumb and the index fin- } \\
\text { ger, and extension of the thumb, abduction and } \\
\text { opposition to the base of the 5th finger. }\end{array}$ & $\begin{array}{l}\text { Hand exercises were the most cost-effective } \\
\text { treatment strategies over } 12 \text { months when com- } \\
\text { pared to alternative methodological approach- } \\
\text { es. }\end{array}$ \\
\hline
\end{tabular}

$\overline{C G}=$ Control Group; IG = Intervention Group.

\section{DISCUSSION}

The objective of this review was to update the concepts on OA of the hands and analyze the studies that used the strengthening of the hand muscles as a non-pharmacological treatment for this disease. This compilation can help health professionals in making decisions about the best approach to monitor $\mathrm{OA}$ and may be used in further studies for comparison of results. Studies addressing this subject are scarce in the literature $^{21}$, and the limited amount of studies make it difficult to discuss the subject.

$\mathrm{OA}$ of the hands is a progressive and irreversible disease that increases fatigue, reduces muscle strength, the range of motion and the resistance of the individual due to the pain and inflammation caused by the disease ${ }^{7}$.

Stukstette et al. ${ }^{17}$ state that studies on OA of the hands frequently relate the reduction of the range of motion and palmar prehension strength with the difficulties presented by the studied patients. Furthermore, they commonly analyzed the disease self-management, exercises for the range of motion, the increment of muscle strength, education and ergonomic principles.

One study included 150 patients with OA of the hands where the effect of the exercise associated with multiple interventions compared to joint protection recommendation. The patients of the control group had only one session on OA recommendations, and the intervention group had recommendation sessions on self-management, ergonomics, home exercises to improve strength and the range of motion, and the use of the orthosis. After a three-month follow-up, the results were insufficient to confirm the importance or the clinical relevance of the short-term treatment in a multidisciplinary program ${ }^{17}$.

Other authors reported the increase of palmar prehension after an intervention with education, a set of exercises associated with joint protection ${ }^{8,22}$. Systematic reviews and meta-analyses have shown the beneficial effect of physiotherapy to improve pain and functionality of OA in the lower limbs, especially for the knees. However, the recommendation of exercises for OA of the hands is still based on recommendation guides on the clinical experience in the treatment of the disease ${ }^{21,23}$. In 2009, a study concluded that there is no evidence in high-quality studies that validate the use of non-pharmacological and non-surgical interventions for OA of the hands. These interventions, despite the small size of the effect, caused less adverse implications for the patient ${ }^{21}$.

A current study showed that three distinct latent functional domains must be evaluated in elderly with $\mathrm{OA}$ of the hands: strength, coordinated function of upper extremity and sensorimotor processing ${ }^{24}$.

Kjeken et al. ${ }^{25}$ described a treatment program with hand exercises for patients with OA. The program had three exercises to increase strength and stability of the shoulder, arm and wrist muscles, and four exercises to keep or to increase the range of motion, prehension and joint stability of the finger joints. The program started with a warm-up and stretching period, and finished with a finger exercise, following the recommendations of the American College Sports Medicine, on the intensity of the exercise, the frequency of the session and the duration of the exercise period.

According to Carreira, Jones and Natour ${ }^{18}$, the effect of the muscle strengthening exercises for OA of the hands, combined with other non-pharmacological alternatives, as for example, the use of orthosis and joint protection techniques have its evidence based on the literature which results are still doubtful.

A systematic review analyzed the effect of non-surgical therapies for OA of the hands. of the 44 studies assessed, only four were selected due to poor methodological quality and plurality in the interventions (exercises for OA of the hands, including Yoga, resistance exercises, and occupational therapy). The result of the analysis of these studies showed "some" evidence for muscle 
strengthening exercises because the methods used for randomization, blindness and allocation hiding were rarely described and a meta-analysis could not be performed since most of the studied treatments were not similar to allow data grouping ${ }^{26}$.

In the systematic review by Valdes and Marik ${ }^{27}$, of the 204 articles recovered dated between 1986 and 2009, 21 studies were included for full analysis and it was observed the effect of exercises for OA of the hands, with a moderate level of evidence for the increase in palmar prehension, function, range of motion and reduction of the pain picture. However, the evaluated studies used multiple treatment interventions, for example, strengthening and range of motion exercises associated with recommendations to protect the joint and application of heat (thermotherapy).

In 2011, a systematic review evaluated pain and function improvement in individuals with $\mathrm{OA}$ of the hands. In this review, 10 studies with an evidence level of $2 b$ or higher, that compared a rehab intervention with a control group and evaluated at least one of the following result measures: pain, hand function or other measures of hand impairment. In addition, the eligibility and the methodological quality of the trials were systematically evaluated by two independent reviewers using the Physiotherapy Evidence Database (PEDro). After the analysis, the authors concluded that in relation to the studies that used the exercise as a treatment technique, no significant effect was found in the applied modalities?

Østerås et al. ${ }^{12}$ concluded that the effects of exercises for OA of the hands are limited. In this study, 130 patients were recruited and divided into a control group (with no intervention) and an exercise group. The patients were followed for three months with the intervention. The exercises performed were not specific to the hands. The program associated with the hand therapy included exercises for brachial biceps strengthening, shoulder flexors and extensors, and range of motion and hand strengthening exercises. However, over the intervention period, only three sessions had professional assistance, in the first, the third and the eighth week. The other exercise sessions were held at home with no supervision.

One recent study evaluated the effect of the exercise combined with joint protection recommendations for treatment of $\mathrm{OA}$ of the hands in four groups: 1. Joint protection, 2. Hand exercises, 3. Joint protection combined with hand exercises, and 4. With no intervention. There were physical attendance sessions, but the base was sessions at home. The function, pain, grasp and prehension were evaluated, as well as the dexterity of these individuals. With the outcome in 12 weeks, the authors saw no differences in the increase of muscle strength, dexterity and function of these patients ${ }^{19}$.

Therefore, when analyzing the results presented, it was observed that although the muscle strengthening exercises are recommended by the guidelines for the treatment of OA of the hands, in order to provide the functional improvement of patients with the disease, very few research still support this affirmation.

Oppong et al. ${ }^{20}$ evaluated the cost of the treatments for OA of the hands and showed that hand exercises were the most cost-effective when compared to alternative approaches. According to Kjeken et al. ${ }^{11}$, the conclusion of the evidence on the use of exercises in the treatment of OA of the hands still presents studies with a high bias risk that do not allow the conduction of meta-analyses to confirm the effect of exercises in the reduction of pain, improvement of strength and range of motion since the studies have demonstrated a lack of consensus in the outline of exercise programs for OA of the hands. Therefore, considering the insufficient amount of studies addressing OA of the hands ${ }^{21}$ and in view of the prevalence and impact of the disease, there is a need for more studies on this subject ${ }^{23}$.

\section{CONCLUSION}

Even though muscle strengthening exercises are recommended for the functional improvement of patients with OA of the hands, very few studies support this affirmation. We found studies with low methodological quality, amount of distinct exercise protocols and lack of systematic reviews with assertive conclusions for the use of muscle strengthening exercises in the treatment of $\mathrm{OA}$ of hands.

\section{REFERENCES}

1. Altman R, Alarcón G, Appelrouth D, Bloch D, Borenstein D, Brandt K, et al. The American College of Rheumatology criteria for the classification and reporting of osteoarthritis of the hand. Arthritis Rheum. 1990;33(11):1601-10.

2. Rogers MW, Wilder FV. Exercise and hand osteoarthritis symptomatology: a controlled crossover trial. J Hand Ther. 2009;22(1):10-20.

3. Leung GJ, Rainsford KD, Kean WF. Osteoarthritis of the hand I: aetiology and pathogenesis, risk factors, investigation and diagnosis. J Pharm Pharmacol. 2014;66(3):339-46.

4. Beasley J. Osteoarthritis and rheumatoid arthritis: conservative therapeutic management. J Hand Ther. 2012;25(2):163-72.

5. Hart DJ, Spector TD. Definition and epidemiology of osteoarthritis of the hand: a review. Osteoarthrits Cartilage. 2000;8(Suppl A):S2-7.

6. Hodkinson B, Maheu E, Michon M, Carrat F, Berenbaum F. Assessment and determinants of aesthetic discomfort in hand osteoarthritis. Ann Rheum Dis. 2012;71(1):45-9.

7. Valdes AM, Lecturer S, Spector TD. The clinical relevance of genetic susceptibility to osteoarthritis. Best Prac Res Clin Rheum. 2010;24(1):3-14.

8. Boustedt C, Nordenskiöld U, Lundgren Nilsson A. Effects of a hand-joint protection programme with an addition of splinting and exercise: one year follow-up. Clin Rheumatol. 2009;28(7):793-9.

9. Ye L, Kalichman L, Spittle A, Dobson F, Bennell K. Effects of rehabilitative intervention on pain, function and physical impairments in people with hand osteoarthritis: a systematic review. Arthritis Res Ther. 2011;13(1):R28.

10. Zhang W, Doherty M, Leeb BF, Alekseeva L, Arden NK, Bijlsma JW, et al. EULAR evidence-based recommendations for the diagnosis of hand osteoarthritis: report of a task force of ESCISIT. Ann Rheum Dis. 2009;68(1):8-17.

11. Kjeken I, Smedslund G, Moe RH, Slatkowsky-Christensen B, Uhlig T, Hagen KB. Systematic review of design and effects of splints and exercise programs in hand osteoarthritis. Arthritis Care Res. 2011;63(6)834-48.

12. Østerås N, Hagen KB, Grotle M, Sand-Svartrud AL, Mowinckel P, Kjeken I. Limited effects of exercises in people with hand osteoarthritis: results from a randomized controlled trial. Osteoarthritis Cartilage. 2014;22(9):1224-33.

13. Hochberg MC, Altman RD, April KT, Benkhalti M, Guyatt G, McGowan J, et al. American College of Rheumatology 2012 recommendations for the use of nonpharmacologic and pharmacologic therapies in osteoarthritis of the hand, hip and knee. Arthritis Care Res. 2012;64(4):465-74

14. Zhang W, Doherty M, Leeb BF, Alekseeva L, Arden NK, Bijlsma JW, et al. EULAR evidence-based recommendations for the management of hand osteoarthritis: report of a task force of the EULAR Standing Committee for international clinical studies including therapeutics (ESCISIT). Ann Reum Dis. 2007;66(3):377-88.

15. Mazocco L, Chagas P. Terapia nutricional na reabilitaçâo de doenças crônicas osteoarticulares em idosos. RBCEH, Passo Fundo. 2015;12(3):309-17.

16. Green JA, Hirst-Jones KL, Davidson RK, Jupp O, Bao Y, MacGregor AJ, et al. The potential for dietary factors to prevent or treat osteoarthritis. Proc Nutr Soc. 2014;73(2):278-88.

17. Stukstette MJ, Dekker J, den Broeder AA, Westeneng JM, Bijlsma JW, van den Ende $\mathrm{CH}$. No evidence for the effectiveness of a multidisciplinary group-based treatment program in patients with osteoarthritis of hands on short term; results of a randomized controlled trial. Osteoarthritis Cartilage. 2013;21(7):901-10. 
18. Carreira AC, Jones A, Natour J. Assessment of the effectiveness of a functional splint for osteoarthritis of the trapeziometacarpal joint of the dominant hand: a randomized controlled study. J Rehabil Med. 2010;42(5):469-74.

19. Dziedzic K, Nicholls E, Hill S, Hammond A, Handy J, Thomas E, et al. Self-management approaches for osteoarthritis in the hand: a $2 \times 2$ factorial randomised trial. Ann Rheum Dis. 2015;74(1):108-18.

20. Oppong R, Jowett S, Nicholls E, Whitehurst DG, Hill S, Hammond A, et al. Joint protection and hand exercises for hand osteoarthritis: an economic evaluation comparing methods for the analysis of factorial trials. Rheumatology (Oxford). 2015;54(5):876-83.

21. Bennell KL, Dobson F, Hinman RS. Exercise in osteoarthritis: moving from prescription to adherence. Best Pract Res Clin Rheumatol. 2014;28(1):93-117.

22. Rogers MW, Wilder FV. The effects of strength training among persons with hand osteoarthritis: a two-year follow-up study. J Hand Ther. 2007;20(3):244-9.
23. Moe RH, Kjeken I, Uhlig T, Hagen KB. There is inadequate evidence to determine the effectiveness of nonpharmacological and nonsurgical interventions for hand osteoarthritis: an overview of high-quality systematic reviews. Phys Ther. 2009;89(12):1363-70.

24. Lawrence EL, Dayanidhi S, Fassola I, Requejo P, Leclercq C, Winstein CJ, et al. Outcome measures for hand function naturally reveal three latent domains in older adults: strength, coordinated upper extremity function, and sensorimotor processing. Front Aging Neurosci. 2015;7:108.

25. Kjeken I, Grotle M, Hagen KB, Østerås N. Development of an evidence-based exercise programme for people with hand osteoarthritis. Scand J Occup Ther. 2015;22(2):103-16.

26. Mahendira D, Towheed TE. Systematic review of non-surgical therapies for osteoarthritis of the hand: an update. Osteoarthritis Cartilage. 2009;17(10):1263-8.

27. Valdes K, Marik T. A systematic review of conservative interventions for osteoarthritis of the hand. J Hand Ther. 2010;23(4):334-50. 